\title{
Deacidification of High-acid Olive Oil
}

\author{
Ahmed Samy M. Abd El-Salam, Mahmoud A. Doheim, Mahmoud Z. Sitohy and Mohamed Fawzy Ramadan*
}

Agricultural Biochemistry Department, Faculty of Agriculture, Zagazig University, Zagazig 44519, Egypt

\begin{abstract}
The objective of the present work was to improve the quality of high-free fatty acid olive (HFFAO) oil. Silica gel (SG) was used as adsorbent by applying filtration and stirring techniques. Chemical treatments with alkali using $\mathrm{NaOH}$ and/or $\mathrm{Ca}(\mathrm{OH})$, were also conducted to neutralize the acidity of HFFAO oil. The percentages of linoleic acid (C18:2) in the neutralized oils were lower than those in the reference olive oil. Untreated and treated HFFAO oil samples were stored under accelerated conditions for 30 days. The progress of oxidation at $60^{\circ} \mathrm{C}$ was followed by measuring acid value (AV), the formation of oxidative products (peroxide value (PV) and $p$-anisidine value (AnV)), total phenolic compounds (TPC), recording radical scavenging activity (RSA) toward 1,1-diphenyl-2-picrylhydrazyl (DPPH) radical and inhibition of $\beta$-carotene in a linoleate model system. The results indicated that SG and alkali treatments were effective in reducing the acidity of HFFAO oil. Generally, alkali treatments reduced the AV of HFFAO oil, while treatments with SG induced variable degrees of improvements in HFFAO oil acidity. Alkali treatments resulted in increasing the PV levels to 35 and 28 meq peroxide $\mathrm{kg}^{-1}$ oil for HFFAO treated with soda and lime, respectively. The corresponding improvement in the PV reduction (\%) for HFFAO oil using SG was in the range of $10.5 \%$ to $47.3 \%$.Treatments with SG or alkali resulted in reduction of AnV, wherein filtration with SG had a remarkable effect on AnV. Levels of TPC were reduced (ca. $70 \%$ ) with alkali treatments, while treatments with SG resulted in reduction of about 22-48\%. Antiradical properties of HFFAO oils were compared using stable DPPH free radicals. After 60 min incubation with DPPH, $78 \%$ of DPPH radicals were quenched by control sample, while HFFAO oils treated with SG or alkali were able to quench from 48 to $56 \%$. Different SG and alkali treatments were not effective in inhibiting the oxidation of linoleic acid and the subsequent bleaching of $\beta$-carotene in comparison with the control. During autoxidation experiments the same trends of results was noted for both control and treated oils.

Practical application: Olive oil is one of the most important edible oils in the world. Crude vegetable oils refined to remove free fatty acids (FFA) as well as other impurities that affect flavor, odor and appearance of oils. Deacidification process significantly influences the economics of oil production. Several methods to remove FFA have been developed to enhance the value of degraded vegetable oils, for example, physical refining based on distillation and chemical refining with sodium hydroxide. In this work, the quality of high-free fatty acid olive (HFFAO) oil was improved using silica gel (SG) as an adsorbent by applying filtration and stirring methods. The results stated that SG with small particle size permitted high adsorbing capacity and close to that induced with chemical treatments which are used commercially in a large scale to improve oil quality.
\end{abstract}

Keywords: High free fatty acid olive oil; Silica gel; Alkali treatment; Acidity; Oxidation; Phenolic compounds; Radical scavenging activity

\section{Introduction}

The world productions of olive oil reach 2,800,000 ton and $98 \%$ of this production is to be found in the Mediterranean basin, where this agricultural system has been developed for thousands of years, characterized by its adaptation to the environment and its empiricism. Several factors have modified the olive production and processing systems in the last decades. The crisis of traditional agriculture and the valorisation of olive oil, due to its organoleptic attributes and its beneficial influence on health, are probably the two most important features. As a consequence great advances have been made in olive oil technology.

Degumming, neutralization, bleaching and deodorization are typical refining steps of oil processing. Crude oil must be refined to remove free fatty acids (FFA) and other impurities that impact on flavor, odor and appearance. Thus, the deacidification process significantly influences the economics of vegetable oil production. The purpose of deacidification in the conventional chemical process is to remove non-glyceride impurities consisting of FFA that contribute to bitter and soapy flavor in food [1]. Conventional approaches to refining include degumming, dewaxing, alkali refining, bleaching, and deodorization, and are best used with low-FFA oils. Several methods to remove FFA have been developed to enhance the value of degraded vegetable oils, for example, physical refining based on distillation and chemical refining with soda (sodium hydroxide). Distillation is an effective method to neutralize vegetable oils with high acidity, but this operation is also energy intensive. Moreover, heating oil to high temperature under reduced pressure generates secondary reactions that alter their physicochemical characteristics and organoleptic properties [2]. Pretreatment with alkali prior to membrane filtration resulted in a very high reduction (ca. 90\%) of FFA in the processed oils [3,4]. These approaches, however, lead to high refining loss when applied to high-FFA oils. Therefore, several authors have proposed physical refining for high-FFA oils [5-8]. This process removes FFA along with odoriferous compounds by purging saturated steam through the oil at

*Corresponding author: Mohamed Fawzy Ramadan, Biochemistry Department, Faculty of Agriculture, Zagazig University, 44519 Zagazig, Egypt, Tel: 002012 9782424 or 002055 2320282; Fax: 0020552287567 or 002055 2345452; E-mail: hassanienmohamed@yahoo.com

Received October 15, 2011; Accepted November 15, 2011; Published November 18, 2011

Citation: Abd El-Salam ASM, Doheim MA, Sitohy MZ, Ramadan MF (2011) Deacidification of High-acid Olive Oil. J Food Process Technol S5-001. doi:10.4172/2157-7110.S5-001

Copyright: (c) 2011 Abd El-Salam ASM, et al. This is an open-access article distributed under the terms of the Creative Commons Attribution License, which permits unrestricted use, distribution, and reproduction in any medium, provided the original author and source are credited. 
a high temperature under high vacuum. Physical refining, however, results in large quantities of distilled fatty acids with concomitant reduction in the quantity of the original oil, especially if the oil being processed is high in FFA content. Alternative approaches have been proposed to reduce neutral oil loss during physical refining. Liquidliquid extraction with polar solvents (e.g., azeotropic isopropanol) was a better process for extracting FFA along with color and peroxide bodies. Treating frying oil with a mixture of gel-derived alumina and activated clay or magnesium silicate had a significant reduction in the amount of fatty acids, aldehydes, ketones and odor- and color-forming compounds [9]. Lin et al. [10] used combinations of four commonly used filter aids (Britesorb, Hubersorb, Frypowder and Magnesol) to recover the used frying oils, where in the levels of FFA were reduced by $82.6-87.6 \%$.

Care must be taken in the selection of filter aids because some of these substances can affect the potential stability of the fats [11]. Clay minerals having these properties are able to adsorb particular amount of trace metals, to reduce the components giving color and chlorophyll, to remove soap and phosphates and to have the effect of reducing FFA to a certain extent [12]. Sepiolite, represented by $\mathrm{Si}_{12} \mathrm{Mg}_{8} \mathrm{O}_{30}(\mathrm{OH})_{4}\left(\mathrm{H}_{2} \mathrm{O}\right)_{4} 8 \mathrm{H}_{2} \mathrm{O}$ which belongs to the group of silicate, is widely used to remove undesired components from household and industrial wastewaters and in various industrial manufacturing processes, it has not been previously tested for the purification of edible oils [13]. The highly desirable tocopherols were reduced during soybean oil refining, and this removal reduces oxidative stability and nutritional value of the refined oil when compared with the crude oil [14]. Tocopherols are more volatile than the neutral triacylglycerides and can be removed with the high temperature and high vacuum of deodorization. Short exposure of the oil to heating is desirable to reduce this loss.

Virgin olive oil is consumed unrefined, although a great proportion of the olive oil produced has to be refined to render it edible. Refining treatments are needed to remove or reduce the content of minor substances that may affect oil quality, such as phospholipids, FFA, pigments, peroxides, traces of metals, herbicides and volatile components. Phenolic compounds are among the substances eliminated during the different refining steps [15]. At present, three types of olive oils are intended for refining: lampante olive oil, olive pomace oil and second centrifugation olive oil. Lampante olive oil is obtained from fruits by mechanical means, but it has undesirable organoleptic or chemical characteristics that make it unfit for consumption. Likewise, the olive paste obtained during the dual-phase centrifugation system used for olive oil extraction is stored for months and subjected to chemical extraction with hexane to produce the traditional olivepomace oil [16], or it can also undergo a new second centrifugation to yield a second centrifugation olive oil [17]. Olive-residue oil has a high percentage of FFA, ranging from 5 to $60 \%$ by weight [18]. The elimination of FFA is the most important refining operation.

Due to the increase in oil price and the environmental concerns the present study was carried out to improve the quality of HFFAO oil and to assess the feasibility of deacidification of the HFFAO oil using inorganic normal silica gel (SG) regeneration agent by applying filtering and stirring techniques. The efficacy of the aforementioned regeneration agent was compared and their mode of action is discussed. In addition, the objective of this study was to examine changes in qualities of HFFAO oil and treated HFFAO oil during storage under accelerated oxidation conditions.

\section{Material and Methods}

\section{Materials}

Lampante high free fatty acid olive (HFFAO) oil was obtained from El-Salheya olive oil Company (El-Salhya City, Sharkia Governorate, Egypt). The peroxide value of the oil was 19 meq peroxide $\mathrm{kg}^{-1}$ oil and the acid value was $3 \mathrm{mg} \mathrm{KOH} \mathrm{g}{ }^{-1}$ oil, respectively. Silica gel (60120 mesh) was purchased from BDH Chemicals Ltd (Poole, UK). All solvents and reagents from various suppliers were of the highest purity needed for each application and used without further purification.

\section{Deacidification of HFFAO oil with SG}

Filtration: Silica gel was activated by heating at $120^{\circ} \mathrm{C}$ for $2 \mathrm{~h}$. Glass chromatographic column $(50 \mathrm{~cm} \times 10 \mathrm{~cm})$ was filled with activated SG and HFFAO oil samples dissolved in hexane (3 g oil: $1 \mathrm{~mL}$ hexane) were filtered through SG. This process was repeated three times using two ratios of SG to HFFAO (1:2 and 1:3, w/w).

Stirring: Silica gel (SG) were added individually to the HFFAO oil (3 g oil: $1 \mathrm{~mL}$ hexane) and mechanically stirred on magnetic stirrer for $120 \mathrm{~min}$ at $25^{\circ} \mathrm{C}$ then filtered through Whatman No. 1 filter paper. This process was repeated three times using two ratios of SG to HFFAO (1:2 and $1: 3, w / w)$. The untreated HFFAO oil was also filtered through Whatman No. 1 filter paper.

\section{Neutralization of HFFAO oil using $\mathrm{NaOH}$ and $\mathrm{Ca}(\mathrm{OH})_{2}$}

Alkali treatments using $\mathrm{NaOH}$ and $\mathrm{Ca}(\mathrm{OH})_{2}$, were conducted to neutralize and modify the acidity of HFFAO. Neutralization with soda $(\mathrm{NaOH})$ and/or lime $\mathrm{Ca}(\mathrm{OH})_{2}$ was carried out as follow: one gram of hydroxide sodium or lime was dissolved in $1 \mathrm{~mL}$ distilled water then the mixture was added to $150 \mathrm{~g}$ olive oil and stirred for $30 \mathrm{~min}$. Hexane $(15 \mathrm{~mL})$ was added and the mixture was stirred for $30 \mathrm{~min}$. The mixture was centrifuged at $3500 \mathrm{rpm}$ for $30 \mathrm{~min}$ and hexane was evaporated and the oil was used for further analyses.

\section{Oxidation experiments}

Samples of HFFAO and untreated HFFAO oils were placed in a series of transparent glass bottles having a volume $20 \mathrm{~mL}$ each. The bottles were completely filled with oil and sealed. No headspace was left in the bottles. The oxidation reaction was accelerated in a forced-draft air oven T6 (Heraeus Instruments GmbH; Hanau, Germany) set at 60 $\pm 2^{\circ} \mathrm{C}$ for up to $0,7,14$ and 30 days. Immediately after storage period, oil samples were withdrawn for triplicate analyses.

\section{Analytical procedures}

The progress of the oxidative deterioration of the oils during storage was followed by measuring the following parameters.

Fatty acid composition: Fatty acids were transesterified into FAME using N-trimethylsulfoniumhydroxide (TMSH, MachereyNagel, Düren, Germany) according to the procedure reported by Arens et al. [19]. In brief, $10 \mathrm{mg}$ of oil sample was dissolved in $500 \mu \mathrm{L}$ of tert.Butyl methyl ether then $250 \mu \mathrm{L}$ of TMSH was added and the mixture was vortexed for 30 seconds before injection. FAME was identified on a Shimadzu GC-14A equipped with flame ionization detector (FID) and C-R4AX chromatopac integrator (Kyoto, Japan). The flow rate of the carrier gas helium was $0.6 \mathrm{~mL} / \mathrm{min}$ and the split value with a ratio of 1:40. A sample of $1 \mu \mathrm{L}$ was injected on a $30 \mathrm{~m} \times 0.25 \mathrm{~mm} \times 0.2 \mu \mathrm{m}$ film thickness Supelco SP ${ }^{\mathrm{TM}}-2380$ (Bellefonte, PA, USA) capillary column. The injector and FID temperature was set at $250^{\circ} \mathrm{C}$. The initial column 
temperature was $100^{\circ} \mathrm{C}$ programmed by $5^{\circ} \mathrm{C} / \mathrm{min}$ until $175^{\circ} \mathrm{C}$ and kept $10 \mathrm{~min}$ at $175^{\circ} \mathrm{C}$, then $8^{\circ} \mathrm{C} / \mathrm{min}$ until $220^{\circ} \mathrm{C}$ and kept $10 \mathrm{~min}$ at $220^{\circ} \mathrm{C}$. A comparison between the retention times of the samples with those of reference compounds mixture, run on the same column under the same conditions, was made to facilitate identification.

Acid value: A known weight of oil sample $(\sim 2 \mathrm{~g})$ was dissolved in neutralised alcohol $(50 \mathrm{~mL})$ and titrated with $\mathrm{KOH}\left(0.1 \mathrm{~mol} \mathrm{~L}^{-1}\right)$ according to AOAC [20].

Peroxide value and p-anisidine value: A known weight of oil sample (ca. $2 \mathrm{~g}$ ) was dissolved in $30 \mathrm{~mL}$ chloroform: acetic acid (3:2, $\mathrm{v} / \mathrm{v}$ ) then $1 \mathrm{~mL}$ freshly prepared saturated KI solution was added and the mixture vortexed for exactly $1 \mathrm{~min}$. Distilled water $(30 \mathrm{~mL})$ and starch solution $(0.5 \mathrm{~mL}, 1 \%)$ were added and the liberated iodine was titrated with sodium thiosulfate $\left(0.1 \mathrm{~mol} \mathrm{~L}^{-1}\right)$ according to AOAC [20]. p-Anisidine value (AnV) was measured according to the official methods of the American Oil Chemists' Society [21].

Total phenolics: Aliquots of oil (2 g) were dissolved in n-hexane (5 $\mathrm{mL})$ and mixed with $10 \mathrm{~mL}$ methanol-water $(80: 20, \mathrm{v} / \mathrm{v})$ in a glass tube for two min in a vortex. After centrifugation at $3000 \mathrm{rpm}$ for $10 \mathrm{~min}$, the hydroalcoholic extracts were separated from the lipid phase by using Pasteur pipet then combined and concentrated in vacuo at $35^{\circ} \mathrm{C}$ until a syrup consistency was reached. The lipidic residue was redissolved in $10 \mathrm{~mL}$ methanol-water $(80: 20, \mathrm{v} / \mathrm{v})$ and the extraction was repeated twice. Hydroalcoholic extracts were redissolved in acetonitrile (15 $\mathrm{mL})$ and the mixture was washed with $\mathrm{n}$-hexane three times $(15 \mathrm{~mL}$ each). Purified phenols in acetonitrile were concentrated in vacuo at $30^{\circ} \mathrm{C}$ then dissolved in methanol for further analysis. Aliquots $(0.2$ $\mathrm{mL}$ ) of phenolic extracts were evaporated to dryness under nitrogen. The residue was redissolved in $0.2 \mathrm{~mL}$ water and diluted (1:30) FolinCiocalteu's phenol reagent $(1 \mathrm{~mL})$ was added. After $3 \mathrm{~min}, 7.5 \%$ sodium carbonate $(0.8 \mathrm{~mL})$ was added. After a further $30 \mathrm{~min}$, the absorbance was measured at $765 \mathrm{~nm}$ using UV-260 visible recording spectrophotometer (Shimadzu, Kyoto, Japan). Caffeic acid was used for the calibration and the results of triplicate analyses are expressed as parts per million of caffeic acid.

\section{Determination of the antioxidant activity}

$\boldsymbol{\beta}$-Carotene-linoleic acid assay: The antioxidant activity of HFFAO oils was evaluated using the $\beta$-carotene-linoleic acid assay. Approximately $2 \mathrm{mg} \beta$-carotene were dissolved in $10 \mathrm{~mL}$ of chloroform. One milliliter of this solution was pipetted into a round bottom flask. After removal of chloroform using a rotary evaporator, $20 \mathrm{mg}$ of linoleic acid, $200 \mathrm{mg}$ of Tween 40 and $50 \mathrm{~mL}$ of distilled water were added to the flask with vigorous stirring. Aliquots $(5 \mathrm{~mL})$ of the prepared emulsion were transferred to a series of tubes containing 2 mg of HFFAO oils. The samples were put in a water bath at $50^{\circ} \mathrm{C}$ over a period of $120 \mathrm{~min}$ and the absorbance was read at $470 \mathrm{~nm}$.

Radical scavenging activity (RSA) toward DPPH radical (Spectrophotometric assay): Antiradical action of oil samples were examined by reduction of DPPH in toluene according to Ramadan et al. [22]. Toluenic solution of DPPH radicals was freshly prepared at a concentration of $10^{-4} \mathrm{M}$. The radical, in the absence of antioxidant compounds, was stable for more than $2 \mathrm{~h}$ of normal kinetic assay. For evaluation, $10 \mathrm{mg}$ of oils (in $100 \mu \mathrm{L}$ toluene) was mixed with $390 \mu \mathrm{L}$ toluenic solution of DPPH radicals and the mixture was vortexed for $20 \mathrm{~s}$ at ambient temperature. Against a blank of pure toluene without $\mathrm{DPPH}$, the decrease in absorption at $515 \mathrm{~nm}$ was measured in $1-\mathrm{cm}$ quartz cells after 60 min of mixing using UV-260 visible recording spectrophotometer (Shimadzu, Kyoto, Japan). RSA toward DPPH radicals was estimated from the differences in absorbance of toluenic DPPH solution with or without sample (control) and the inhibition percent was calculated from the following equation: \% inhibition = [(absorbance of control - absorbance of test sample)/ absorbance of control] x 100 .

All results presented are mean values of at least three experiments, wherein no statistically significant difference $(P>0.05)$ was found among the experiments.

\section{Results}

\section{Impact of deacidification on the oil recovery and fatty acid composition of HFFAO}

Applying different SG and alkali treatments resulted in weight losing during different treatments. Table 1 present the percentages of weight losing during processing. Stirring techniques with SG leads to higher percentages of weight losing (16-14\%) followed by filtration technique (13-12\%), while alkali treatments with soda and lime resulted in moderate weight losing (8-7\%). The FA compositions of the oils, before and after neutralization, are shown also in Table 1 . The percentages of linoleic acid (C18:2) in the neutralized oils were lower than those in the reference olive oil. This reduction was more important with SG neutralization. A reduction in the percentage of palmitic acid (C16:0) was noted in the neutralized oils especially in alkali treated oils, as well as a very clear increase in the percentage of oleic acid (C18:1n-9). Most of the free acidity of HFFAO oil might be attributable to palmitic acid and oleic acid. The results are in agreement with Essid et al. (2006) who used lime (calcium hydroxide) and soda (sodium hydroxide) as the neutralizing agent for refining high acid olive oil.

\section{Impact of deacidification on the acid value (AV) of HFFAO}

The most versatile fat chemical characteristics for the determination of olive oil quality are: acid value, peroxide value, anisidin value and phenolics content. It has been reported that humidity of the environment has been reported to be a factor affecting hydrolysis of oils [23]. The initial values of HFFAO were, acid value ( $3 \mathrm{mg} \mathrm{KOH} \mathrm{g}^{-1}$ oil), peroxide value (19 meq peroxide $\mathrm{kg}^{-1}$ oil), anisidin value (20), wherein the total phenolics level $(0.43 \mathrm{mg} / \mathrm{kg}$ as caffeic acid equivalent). These findings indicate that the HFFAO oil was characterized by high level of acidity. Acidic changes taking place in the experiments conducted with SG were investigated. FFA removal profile with SG as well as alkali treatments are plotted in Figure 1. Generally, alkali treatments with soda and/or lime significantly reduced the AV of HFFAO oil. On the other side, treatments with SG induced variable degrees of improvements in HFFAO oil quality. Filtration technique through SG achieved more FFA removal than stirring technique. As seen in the figure, at zero time, maximum FFA removal observed with SG filtration technique (about $57.6 \%$ ) when the ratio $2: 1$ was applied. On the contrary, nearly $21.6 \%$ FFA removal was achieved with SG stirring technique when the ratio 3:1 was applied for control sample SG.

During storage for 30 days under accelerated oxidation conditions at $60^{\circ} \mathrm{C}$ the same levels of reducing acid values of stored samples were recorded. The results demonstrated that the treatment of HFFAO oil with alkali $\left(\mathrm{NaOH}\right.$ and/or $\left.\mathrm{Ca}(\mathrm{OH})_{2}\right)$ greatly lowered the FFA levels. The effect of filtration and stirring using SC was nearly the same during the oxidation experiment. 
Citation: Abd El-Salam ASM, Doheim MA, Sitohy MZ, Ramadan MF (2011) Deacidification of High-acid Olive Oil. J Food Process Technol S5-001. doi:10.4172/2157-7110.S5-001

Page 4 of 7

\begin{tabular}{|c|c|c|c|c|c|c|c|c|c|c|c|}
\hline Olive oil & $\begin{array}{l}\% \text { Weight } \\
\text { losing }\end{array}$ & C16:0 & C16:1 & C17:0 & C17:1 & C18:0 & C18:1 & C18:2 & C18:3 & C20:0 & C20:1 \\
\hline HFFAO & 0 & 21.33 & 3.33 & 0.03 & 0.07 & 2.66 & 51.37 & 17.20 & 0.55 & 0.35 & 0.16 \\
\hline $\begin{array}{c}\text { Filtration } \\
2: 1 \text { (oil: } S G, w / w)\end{array}$ & 13 & 20.11 & 3.10 & 0.03 & 0.07 & 2.79 & 55.58 & 12.94 & 0.53 & 0.40 & 0.16 \\
\hline $\begin{array}{c}\text { Filtration } \\
\text { 3:1 (oil: SG, w/w) }\end{array}$ & 12 & 20.21 & 3.00 & 0.02 & 0.08 & 2.89 & 55.48 & 12.74 & 0.73 & 0.41 & 0.15 \\
\hline $\begin{array}{c}\text { Stirring } \\
\text { 2:1 (oil: SG, w/w) }\end{array}$ & 16 & 20.82 & 2.94 & 0.03 & 0.07 & 2.69 & 51.69 & 15.32 & 0.52 & 0.39 & 0.16 \\
\hline $\begin{array}{c}\text { Stirring } \\
\text { 3:1 (oil: } S G, w / w)\end{array}$ & 14 & 20.62 & 2.84 & 0.04 & 0.06 & 2.89 & 51.71 & 15.30 & 0.62 & 0.38 & 0.17 \\
\hline $\begin{array}{c}\text { Oil neutralized with } \\
\mathrm{NaOH}\end{array}$ & 7 & 13.88 & 1.64 & 0.05 & 0.07 & 2.58 & 64.22 & 16.20 & 0.52 & 0.40 & 0.24 \\
\hline $\begin{array}{l}\text { Oil neutralized with } \\
\mathrm{Ca}(\mathrm{OH})_{2}\end{array}$ & 8 & 14.19 & 1.78 & 0.06 & 0.08 & 2.56 & 63.83 & 16.43 & 0.58 & 0.44 & 0.19 \\
\hline
\end{tabular}

Table 1: Fatty acid composition of HFFAO oil and neutralized oils (mass \%).

Impact of deacidification on the peroxide value $(\mathrm{PV})$ and p-anisidine value (AnV)

Peroxides and hydroperoxides, the primary oxidation products, decompose to form aldehydes, ketones, acids, alcohols, hydrocarbons and other compounds. These substances formed during thermal oxidation of oils. The products of oil degradation as defined by International Union of Pure and Applied Chemistry [24] are polar materials. The polar fraction is composed of FFA, monoglycerides, oxidized triglycerides and oligomeric triglycerides. All treatments and regeneration adsorbents used in the present work caused an improvement in stored and treated HFFAO oil quality comparable to that of fresh oil.

The initial PV of HFFAO was 19 meq peroxide $\mathrm{kg}^{-1}$ oil. Alkali treatments with soda and/or lime did not improve the quality HFFAO in the terms of PV but resulted in increasing the PV levels to 35 and $28 \mathrm{meq}$ peroxide $\mathrm{kg}^{-1}$ oil for HFFAO treated with soda and lime, respectively (Figure 2). The corresponding improvement in the PV reduction (\%) for HFFAO oil using SG was in the range of $10.5 \%$ to $47.3 \%$. These results demonstrated that the adsorbing efficiency of SG with small particle size (60-120 mesh) permitted high adsorbing capacity and very good in scavenging the peroxides of HFFAO. Yates et al. [25] added silicates in powdered form and subsequently removed by filtration in order to regenerate the quality of used oils. In this respect, Kalapathy and Proctor [26] prepared sodium silicate films from rice hull ash silica and mentioned that FFA content gradually decreased with treatment time for all films. The PV for the treated oils was progressively increased during storage under accelerated oxidation conditions. However, PV were reduced after 30 days of storage in the samples treated with SG and this finding could be due to the volatilization of some peroxides under accelerated oxidation conditions. The efficiency of various SG: oil ratios (1:2 and 1:3,w/w) on lowering the PV of HFFAO oil was approximately the same at a certain level.

The p-anisidine value $(\mathrm{AnV})$, which measures the unsaturated aldehydes (principally 2-alkenals and 2,4-dienals) in oils, was determined by reacting $\mathrm{p}$-anisidine with the oil in iso-octane and the resultant color was measured at $350 \mathrm{~nm}$. The initial AnV for HFFAO oil was 20 and it could be noted that treatments with SG or alkali resulted in reduction of $\mathrm{AnV}$ (Figure 3). In addition, filtration with SG was more active in reduction of $\mathrm{AnV}$ than stirring technique. During autoxidation at $60^{\circ} \mathrm{C}$ in the dark (Figure 3), treated HFFAO oils were more stable than the control oil. Here again, SG with high polarity led to a higher adsorbing capacity in removing the secondary oxidation products of HFFAO oil. However, at the end of oxidation experiment the AnV levels in treated HFFAO oils (except of oil treated with lime) were higher than control oil. The results demonstrated that all treated HFFAO oils had a potent oxidative stability (OS) higher than control oil. Meanwhile, treatment with SG and alkali caused a decrease in both peroxide and $\mathrm{p}$-anisidine levels during incubation intervals for 30 days.

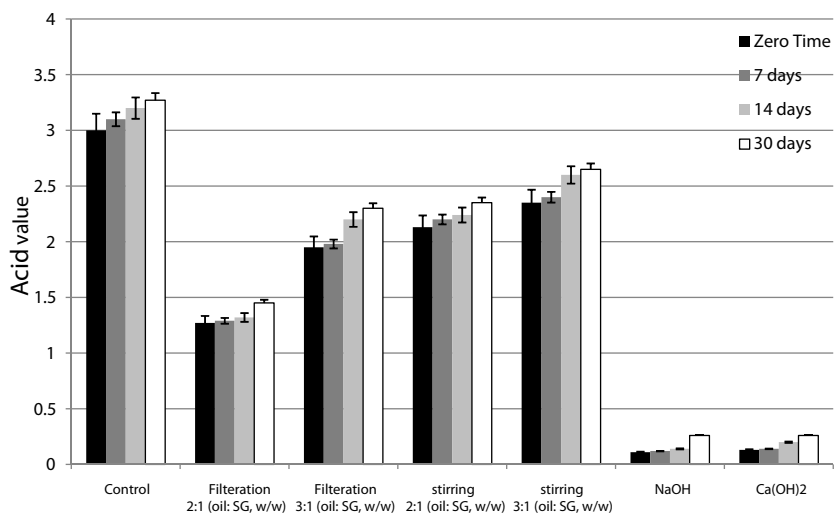

Figure 1: Changes in acidity (AV) of untreated HFFAO and treated HFFAO oils as affected by SG and alkali treatments during oven test. Error bars show the variations of three determinations in terms of standard deviation.

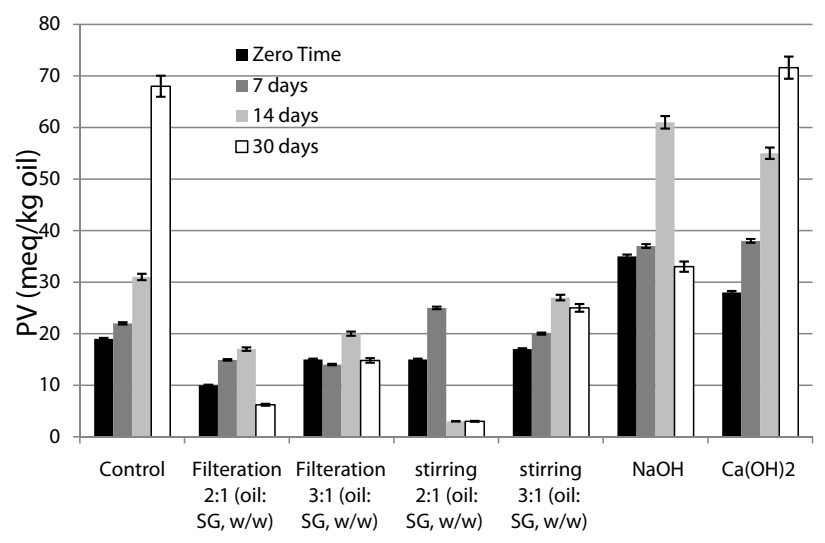

Figure 2: Changes in the PV levels of untreated HFFAO and treated HFFAO oils as affected by SG and alkali treatments during oven test. Error bars show the variations of three determinations in terms of standard deviation. 


\section{Impact of deacidification on the total phenolic compounds (TPC)}

Figure 4 present the impact of different treatments on the TPC of HFFAO oils during oxidation storage. The initial TPC in HFFAO was $43 \mathrm{mg} / \mathrm{kg}$ oil and the levels of TPC were significantly reduced (ca. 70\%) with alkali treatments (soda and lime). Treatments with SG also resulted in relative reduction (ca. 22-48\%) in the TPC levels. During oxidation at $60^{\circ} \mathrm{C}$ (Figure 4), all samples showed a gradual decrease, wherein SG treated HFFAO oils were more stable than alkali treated oils. The TPC content of olive oil determined colorimetrically is reduced almost to zero with refining [27]. Nergiz [28] reported that a residual amount of total polyphenols and o-diphenols can be found in refined olive oils.

Impact of deacidification on the radical scavenging activity (RSA) and inhibition of $\beta$-carotene co-oxidation in a linoleate model system

Interest has increased in the past few years in the free radical theory of disease causation, particularly in vascular diseases and certain forms of cancer. These developments have led to the investigation on dietary

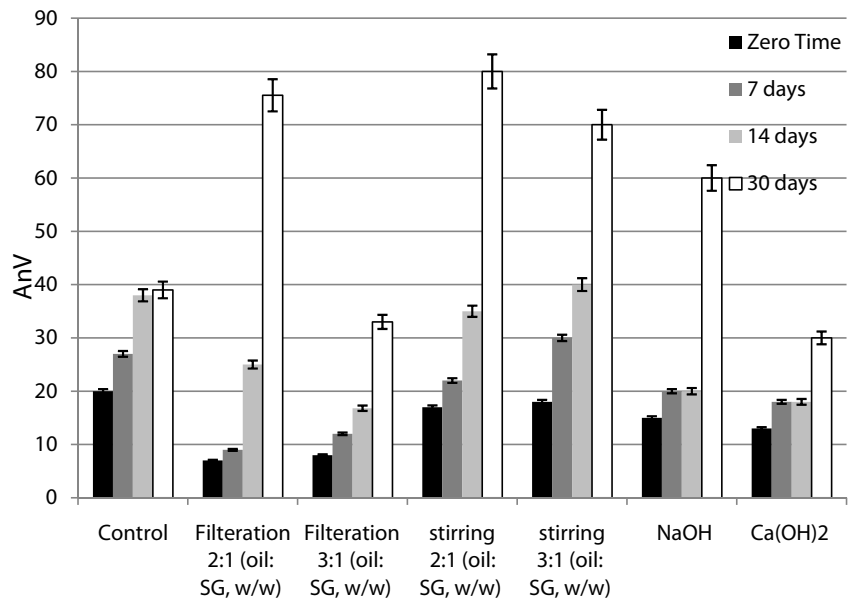

Figure 3: Changes in the AnV levels of untreated HFFAO and treated HFFAO oils as affected by SG and alkali treatments during oven test. Error bars show the variations of three determinations in terms of standard deviation.

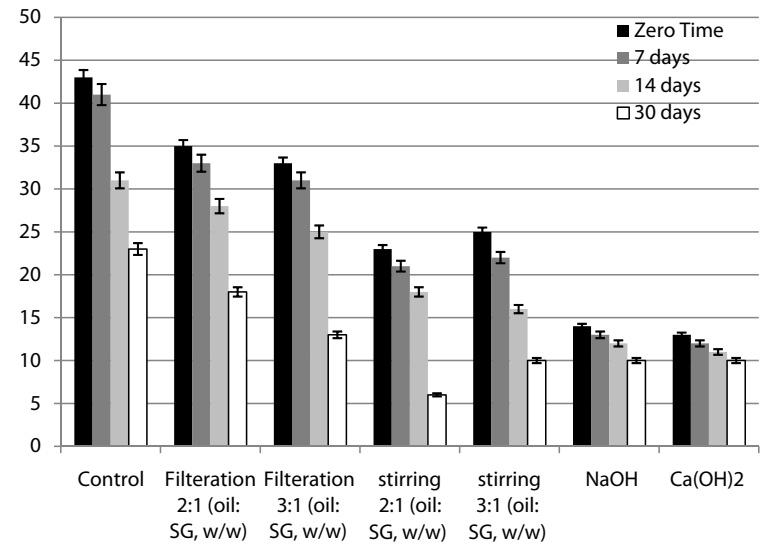

Figure 4: Changes in the amounts of TPC for untreated HFFAO and treated HFFAO oils as affected by SG and alkali treatments during oven test. Error bars show the variations of three determinations in terms of standard deviation.

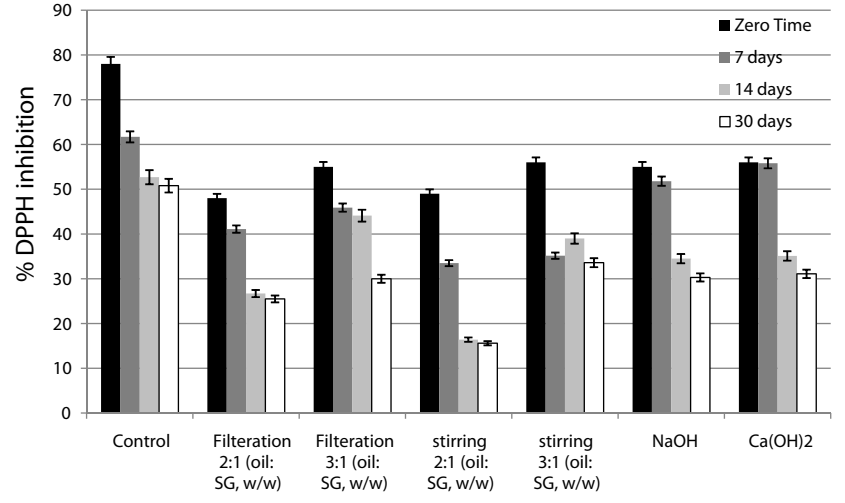

Figure 5: Changes in RSA of untreated HFFAO and treated HFFAO oils as affected by $S G$ and alkali treatments during oven test. Error bars show the variations of three determinations in terms of standard deviation.

agents, the antioxidant nutrients (mainly vitamins $\mathrm{A}, \mathrm{C}$, and $\mathrm{E}$ ), in a possible prophylactic, even curative, role in the disease process. Closely related to this probable benefit of natural antioxidants is their role in controlling free radicals as they may lead to pathological effects such as vascular diseases and cancer. A free radical is defined as any chemical species that has one or more unpaired electrons. This often results in very reactive compounds. Oxidation is a natural and needed reaction in metabolism. Highly reactive hydroxyl radicals, $\bullet \mathrm{OH}$, results. These can attack DNA, protein and polyunsaturated fatty acids residues of membrane phospholipids, among others. With the latter, a peroxyl radical is formed. Antioxidants quench this radical. If the supply of antioxidants is inadequate, a chain reaction takes place that may lead to damaged tissue. The evidence in the literature begins to make an overwhelming case for the existence of a relationship between high blood levels of antioxidant nutrients and a lowered incidence of disease [29]. The antioxidant activity of phenolic compounds may inhibit free radicals from initiating the oxidation process and radical chain reaction. For this reason, two different methods were used for the determination of the antioxidant activity of the extracts: inhibition of $\beta$-carotene co-oxidation in a linoleate model system and DPPH free radical scavenging.

Apart from the OS of vegetable oils and fats depends on the fatty acid composition, the presence of minor fat-soluble bioactives and the initial amount of hydroperoxides. Antiradical properties of HFFAO oil were compared using stable DPPH free radicals. Figure 5 shows that control sample of HFFAO oil has higher RSA than HFFAO oils treated with SG or alkali. After $1 \mathrm{~h}$ incubation, $78 \%$ of DPPH radicals were quenched by control sample of HFFAO oil, while HFFAO oils treated with SG or alkali were able to quench from 48 to $56 \%$ at the same time of incubation. During autoxidation experiment the same trends of RSA was noted for control and treated oil samples. It could be concluded that treatment of HFFAO oils with SG or alkali resulted in reduction in the levels of polar bioactive antioxidants responsible for antiradical action. It could be said that the RSA of oils can be interpreted as the combined action of different endogenous antioxidants. However, when polar fractions, which contain mainly polar lipids and low levels of phenolics, are found in high levels, strong RSA of these components can be expected as well as synergistic activity with primary antioxidants [30,31].

Figures 6 reveal the decrease of absorbance of $\beta$-carotene in the presence of different HFFAO oil in the coupled system of $\beta$-carotene 


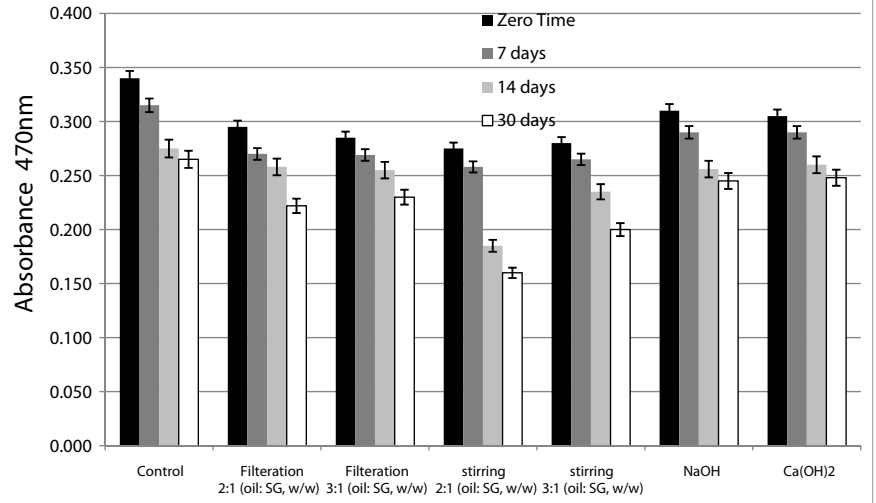

Figure 6: hanges in the bleaching of $\beta$-carotene for untreated HFFAO and treated HFFAO oils as affected by SG and alkali treatments during oven test. Error bars show the variations of three determinations in terms of standard deviation.

and linoleic acid at $50^{\circ} \mathrm{C}$. It shows that the treated HFFAO oxidized most rapidly. Different SG and alkali treatments were not effective in inhibiting the oxidation of linoleic acid and the subsequent bleaching of $\beta$-carotene in comparison with the control. During accelerated oxidation experiment the same trend of results were recoded of all samples wherein untreated samples recorded the highest level of inhibiting the oxidation of linoleic acid. In addition, there was no direct correlation between the level of phenolic compounds in the oils and their antioxidant activity.

\section{Discussion}

The oil production from oilseeds cannot cope with the high demands of oils especially in the developed countries. In addition, recent target of the developed countries is to produce biofuels from vegetable oils which makes the oil crisis even more badly [32,33]. Therefore, any method that extends the useful life of used oils could translate enormous returns for the food services industries. In this respect, several adsorbent agents are used to purify used oils [34,35]. Most of these agents, such as clay, magnesium silicate, activated alumina, charcoal, etc., remove one or more of the impurities or colored bodies. In fact, several reports indicated that adsorbents improved the color and viscosity in respect to those of the fresh oil instead of used oil to the extent of fresh oil [36]. In addition, these materials reduce the total polar materials and oxidation products which normally lead to the deterioration of low quality used oil. It is well accepted that during processing partial hydrolysis of the oil takes place and FFA content increases. Another factor that promotes oil hydrolysis is the presence of moisture. As the crude olive oil in this work was dried over anhydrous sodium sulphate, the effect of moisture will be excluded from the discussion.

Vegetable oils that have been degraded by hydrolysis must be refined before use. Olive-residue oil has a high percentage of FFA, ranging from 5 to $60 \%$ by weight. The elimination of FFA is the most important refining operation. Several methods to remove FFA have been developed to enhance the value of degraded vegetable oils, for example, physical refining based on distillation and chemical refining with soda (sodium hydroxide). Distillation is an effective method to neutralize vegetable oils with high acidity, but this operation is also energy intensive. Moreover, heating oils to high temperature under reduced pressure generates secondary reactions that alter their physicochemical characteristics and organoleptic properties. Thermal and catalytic reactions lead to the formation of olefin hydrocarbons, diand triterpenes, and aromatic products as a consequence of tocotrienol degradation.

Sodium hydroxide not only neutralizes FFA, which is the aim, but also attacks neutral oil by saponification, leading to reduced output and the formation of monoacylglycerols and diacylglycerols in neutral oil. From an economic viewpoint, neutralization with soda in a liquid-liquid biphasic medium cannot be applied to oils having acidity $>15 \%$ because the quantity of neutral oil that is saponified becomes very significant. In addition, soda eliminates some of the principal components responsible for OS, such as tocopherols, and can involve losses of sterols, which constitute $30-60 \%$ of the unsaponifiables. Total sterol losses can be as much as $15 \%$.

The aforementioned data indicated that SG was an effective adsorbing substance in removing secondary oxidation substances from HFFAO oil. Silica gel with 60-120 mesh does not exhibit any harmful effects to the handler and possesses adsorbing efficiency in removing secondary oxidation substances. In addition, the price of normal SG is comparable to Magnesol XL and would therefore be useful for regenerating the quality of used oils and high FFA oils. According to the chemical structure of SG, it exhibits dual functions (polar and non-polar characters). In general, one would say that silica gel with 60-120 mesh had the highest adsorbing capacity than that of other adsorbing agents [37]. In this respect, silica offers the greatest potential for refining the edible oil in industry. It is of interest to note that the silicone atoms of SG are joined via oxygen atoms in a giant covalent structure. However, at the surface of the SG, the silicone atoms are attached to $-\mathrm{OH}$ groups. So, the surface of the SG is very polar and the $-\mathrm{OH}$ groups can form hydrogen bonds with the secondary oxidation products as well as van der Waals dispersion forces and dipole- dipole attractions. In fact, the most important features of SG are the presence of silanol $(\mathrm{Si}-\mathrm{OH})$ groups that are polar and ionisable and siloxane linkage $(\mathrm{Si}-\mathrm{O}-\mathrm{Si})$ that has a hydrophobic character. The following diagram represents the existence of silanol groups (polar) at the surface while the siloxane groups (non-polar) are located at the interior part of the silica gel molecules.

\section{Silanol groups (polar) at the surface of SG}

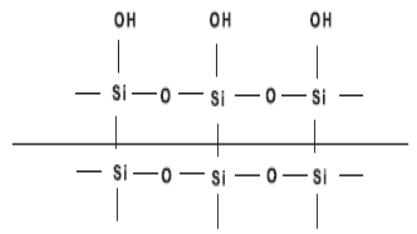

\section{Siloxane groups (non-polar) inside SG molecules}

It is well known that oxidation products are mainly polar and some are non-polar substances. Silica gel molecules have polar and nonpolar groups which associate with the secondary oxidation products according to the well known basis 'likes dissolve likes'. Thus, SG structure allows to great extent improve the quality of oils with high polar levels. It could be concluded that SG with small particle size permitted high adsorbing capacity and close to that induced with chemical treatments which are used commercially in a large scale to improve oil quality. 
Citation: Abd El-Salam ASM, Doheim MA, Sitohy MZ, Ramadan MF (2011) Deacidification of High-acid Olive Oil. J Food Process Technol S5-001. doi:10.4172/2157-7110.S5-001

\section{References}

1. Young FVK, Poot C, Biernoth E, Krog N, Davidson NGJ, et al. (1994) Processing of fats and oils. In: The Lipid Handbook. (2nd Edn.), Gunstone FD, Harwood JL, Padley FB, Chapman \& Hall, London, 281-284.

2. Cecchi G (1998) Transformation of Sterols during the Manufacture of Vegetable Squalene: Incidence of This Transformation on the Presence of Sterane in Squalene Olive Origin. OCL 5: 149-156.

3. Sen Gupta AK (1985) U.S. Patent 4533501

4. Pioch D, Largueze C, Graille J, Ajana H, Rouviere J (1998) Towards an efficient membrane based vegetable oils refining. Industrial Crops and Products 7: 8389.

5. Kim SK, Kim CJ, Cheigh HS, Yoon SH (1985) Effect of Caustic Refining, Solvent Refining, and Steam Refining on the deacidification and Color of Rice Bran Oil. J Am Oil Chem Soc 62: 1492-1495.

6. Tandy DC, McPherson WJ (1984) Physical Refining of Edible Oil. J Am Oi Chem Soc 61: 1253-1258.

7. Cvengros J (1995) Physical Refining of Edible Oils. J Am Oil Chem Soc 72: 1193-1196.

8. De BK, Bhattacharyya DK (1998) Physical Refining of Rice Bran Oil in Relation to Degumming and Dewaxing. J Am Oil Chem Soc 75: 1683-1686.

9. Bhattacharyya AC, Majumdar S, Bhattacharyya DK (1987) Refining of High FFA Rice Bran Oil by Isopropanol Extraction and Alkali Neutralization. Oleagineux 42: 431-433.

10. Lin S, Akoh CC, Reynolds AE (1999) Determination of optimal conditions for selected adsorbent combinations to recover used frying oils. J Am Oil Chem Soc 76: 739-744.

11. Yates RA, Caldwell JD (1993) Regeneration of oils used for deep frying: comparison of active filter aids. J Am Oil Chem Soc 70: 507-511.

12. Rossi M, Gianazza M, Alamprese C, Stanga F (2003) The role of bleaching clays and synthetic silica in palm oil physical refining. Food Chem 82: 291-296.

13. Ugurlu M, Kula I (2007) The removal of colour, carotene and acidity from crude olive oil by using sepiolite. International J Food Sci Technol 42: 359-365.

14. Jung MY, Yoon SH, Min DB (1989) Effect of Processing Steps on the Contents of Minor Compounds and Oxidation of Soybean Oil. J Am Oil Chem Soc 66:118-120.

15. Krishna AGG, Khatoon S, Shiela PM, Sarmandal CV, Indira TN, et al. (2001) Effect of Refining of Crude Rice Bran Oil on the Retention of Oryzanol in the Refined Oil. J Am Oil Chem Soc 78: 127-131.

16. Ruiz-Méndez MV, Dobarganes MC (1999) Olive Oil and Olive Pomace Oi Refining. Oleagineux Corps Gras Lipides 6: 56-60.

17. Alba J, Hidalgo F, Ruiz MA, Martínez F, Moyano MJ, et al. (1996) Características de los aceites de oliva de primera y egunda centrifugación. Grasas y Aceites 47: 163-181.

18. Nefzaoui A (1991) Valorization of By-products of the Olive Tree. CIHEAMMediterranean Options 16: 101-108.

19. Arens M, Schulte E, Weber K (1994) Fettsäuremethylester, umesterung mit trimethylsulfoniumhydroxid (schnellverfahren). Lipid Sci Technol 96: 67-68.

20. A.O.A.C. (2000) Official Methods of Analysis of the Association of Agricultura Chemists. (17th edn), A.O.A.C., Washington, DC.

21. AOCS (2000) Official Methods and Recommended practices of the American Oil Chemists' Society. (4 $4^{\text {th }}$ edn), AOCS: Champaign, IL (USA).

22. Ramadan MF, Mörsel JT (2006) Screening of the antiradical action of vegetable oils. J Food Compost Anal 19: 838-842.

23. Omar S, Girgis B, Taha F (2003) Carbonaceous materials from seed hulls for bleaching of vegetable oils. Food Res Int 36: 11-17.
24. IUPAC (1987) Standard methods for the analysis of oils, fats and derivatives (edited by Paquot C, Hautfenne A). Pure \& Appi Chem 51: 2503-2525.

25. Yates RH, Cadwell YD, Perkins EG (1997) Diffuse reflectance Fourier transform infrared spectroscopy of triglycerol and oleic acid adsorption on synthetic magnesium silicate. J Am Oil Chem Soc 74: 289-292.

26. Kalapathy U, Proctor A (2000) A new method for free fatty acid reduction in frying oil using silicate films produced from rice hull ash. J Am Oil Chem Soc 77: $593-598$

27. Vázquez A, Janer del Valle C, Janer del Valle ML (1973) Determinación de los polifenoles totales del aceite de oliva. Grasas Aceites 24: 350-357.

28. Nergiz C (1993) The Effect of Refining Processes on the Total Polyphenol and 1,2-Diphenol Content of Olive Oil. Int J Food Sci Technol 28: 461-464.

29. Ramadan MF, Mörsel JT (2003) Oil goldenberry (Physalis peruviana L.). J Agric Food Chem 51: 969-974.

30. Ramadan MF, Sharanabasappa G, Seetharam YN, Seshagiri M, Moersel JT (2006) Profile and levels of fatty acids and bioactive constituents in mahua butter from fruit-seeds of Buttercup tree [Madhuca longifolia (Koenig)]. Europ Food Res Technol 222: 710-718.

31. Ramadan MF, Zayed R, El-Shamy H, (2007) Screening of bioactive lipids and radical scavenging potential of some solanaceae plants. Food Chem 103: 885890.

32. Du W, Xu Y, Liu D, Zeng J (2004) Comparative study on lipase-catalyzed transformation of soybean oil for biodiesel production with different acyl acceptors. Journal of Molecular Catalysis B: Enzymatic 30: 125-129.

33. Kim H, Kang B, Kim M, Park YM, Kim D, et al. (2004) Transesterification of vegetable oil to biodiesel using heterogeneous base catalyst. Catalysis Today 93-95: 315-320.

34. Lin S, Akoh CC, Reynolds AE (1999) Determination of optimal conditions fo selected adsorbent combinations to recover used frying oils. J Am Oil Chem Soc 76: 739-744.

35. Bheemreddy RM, Chinnan MS, Pannu KS, Reynolds AE (2002) Active treatment of frying oil for enhanced fry-life. J Food Sci 67: 1478-1484.

36. Farag RS, EL-Anany AM (2006) Improving the quality of fried oils by using different filter aids. J Sci Food Agric 86: 2228-2240.

37. Farag RS, Basuny AMM (2009) Improvement in the quality of used sunflowe oil by organic and inorganic adsorbents. Int J Food Sci Technol 44: 1802-1808.

38. Kent SK (2000) Adsorbent Selections. Dublin, OH: Adsorption Research, Inc. 